\title{
Influence of local peritoneal involvement on pelvic recurrence and prognosis in rectal cancer
}

\author{
N A Shepherd, K J Baxter, S B Love
}

\begin{abstract}
Aims-To evaluate the influence of involvement of the peritoneal surface by carcinoma of the rectum on local recurrence and prognosis.

Methods-Prospective analysis of pathological prognostic factors in 209 resections for rectal carcinoma between 1988 and 1993 with meticulous pathological technique particularly to assess the relation of tumour to the peritoneal surface. Comprehensive clinical follow up with cause of death established from all available sources of information (hospital and general practitioner data) with necropsies where necessary. Local recurrence was determined by accepted clinical, radiological and pathological criteria.
\end{abstract}

Results-Local peritoneal involvement was detected in $25 \cdot 8 \%$ (54/209) of cases. It was more common in women and was associated with tumour differentiation, size and site, and lymph node involvement. Local peritoneal involvement showed considerable prognostic disadvantage in all cases and in curative cases alone. Multivariate analysis demonstrated independent prognostic disadvantage for all cases although this was lost in the curative group. With a 30 month median follow up time, comprehensive clinical surveillance detected $25(12 \cdot 0 \%)$ local recurrences. Thirteen $(52 \%)$ palliative cases had shown spread to involve the mesorectal (deep, circumferential) resection margin. Of the 12 curative cases, six were upper rectal cancers with local peritoneal involvement suggesting that tumour seeding into the pelvic peritoneal cavity was the cause of local recurrence. Local recurrence of the six other rectal tumours was probably because of intraluminal seeding in two, involvement of the distal margin in one, extensive extramural venous involvement in two, and tumour spread to the bladder in one.

Conclusions-Comprehensive pathological analysis of a resection specimen can identify cases with a high probability of local recurrence which may benefit from early adjuvant therapy. Involvement of the peritoneal surface is a common event in rectal cancer, has adverse prognostic influence and may be an important factor in local recurrence of upper rectal carcinoma.

( $(\mathcal{C}$ Clin Pathol 1995;48:849-855)

Keywords: Peritoneal involvement, rectum, carcinoma, peritoneum, local recurrence, prognosis.
Dukes' original staging system ${ }^{1}$ was developed for rectal cancer prognostication and continues to be the most popular staging system in use today. ${ }^{2}$ Along with several subsequent staging classifications, such as the Astler-Coller, ${ }^{3}$ Kirklin-Dockerty, ${ }^{4}$ modified Dukes (Dukes/ Bussey), ${ }^{5}$ and Australian Clinico-Pathological Staging (ACPS) system ${ }^{6}$ classifications, it suffers from its sequential nature, in that the possible prognostic influence of local spread beyond the bowel wall is not taken into account if there is local lymph node involvement. ${ }^{7}$ The inadequacies of these staging systems in assessing the prognostic significance of extensive local spread have been highlighted by the demonstration of the importance of spread within the mesorectum in predicting local (pelvic) recurrence. ${ }^{8}$ Indeed Heald ${ }^{910}$ and others have shown that the surgical practice of complete mesorectal clearance will substantially reduce pelvic recurrence rates. Whilst other factors may predispose to local recurrence after resection of the rectum, ${ }^{112}$ the extent of spread within the mesorectum and involvement of the deep (circumferential, mesorectal) margin are widely believed to be the most important determinants of local recurrence. ${ }^{89}$

Not all the rectum is surrounded by the mesorectum. The peritoneal reflection is situated $5.5 \mathrm{~cm}$ above the dentate line in the female and $7.5 \mathrm{~cm}$ above in the male (fig 1)..$^{13}$ Assuming the rectum to be a uniform cylinder and that half the circumference of the upper rectum is, on average, invested by peritoneum, a simple calculation demonstrates that approximately $25 \%$ of the anatomical rectum is invested by peritoneum in the female and about $16 \%$ in the male. It is therefore surprising that no attention has been previously paid to the involvement of the peritoneal surface by rectal carcinoma as a potential predictor of pelvic recurrence and prognosis. Carcinomatous spread from an advanced upper rectal tumour might be expected to involve the pelvic peritoneum with subsequent seeding of tumour cells into the peritoneal cavity and into the pelvic tissues at the site of the resection. Such a hypothesis is the subject of this prospective investigation into the significance of local peritoneal involvement in rectal carcinoma.

\section{Methods}

The Gloucester Colorectal Cancer Study was established in 1988 to compare and contrast the prognostic influence of clinicopathological factors after surgery for colonic and rectal cancer and, in particular, to examine the influence of peritoneal (serosal) involvement on local (pelvic) recurrence, intraperitoneal spread and 


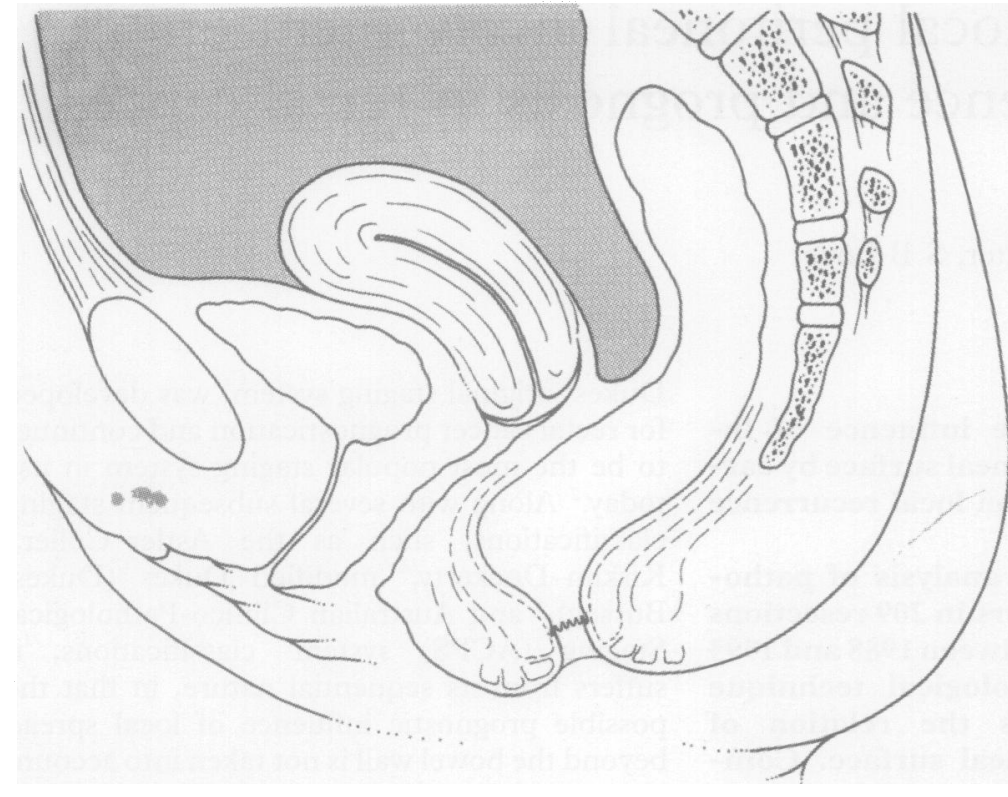

Figure 1 The relation between the visceral peritoneum (shaded) and the rectum in the female pelvis. The peritoneal reflection lies $6.5 \mathrm{~cm}$ below the upper margin of the rectum.

prognosis. Its advantages over other studies are that it is both unselected (in a large District General Hospital) and prospective. Of the 629 patients recruited into the study thus far, 209 patients (M:F ratio, 124:85; mean age 69 years, range 28-93 years) underwent surgery for rectal carcinoma between August 1988 and December 1993 and they are the subjects of the current study. Both curative and palliative cases are included except those in which resection was performed for synchronous carcinoma, metachronous carcinoma and carcinoma arising in ulcerative colitis and familial adenomatous polyposis. In each included case, either anterior resection or abdominoperineal resection had been performed and local ex-

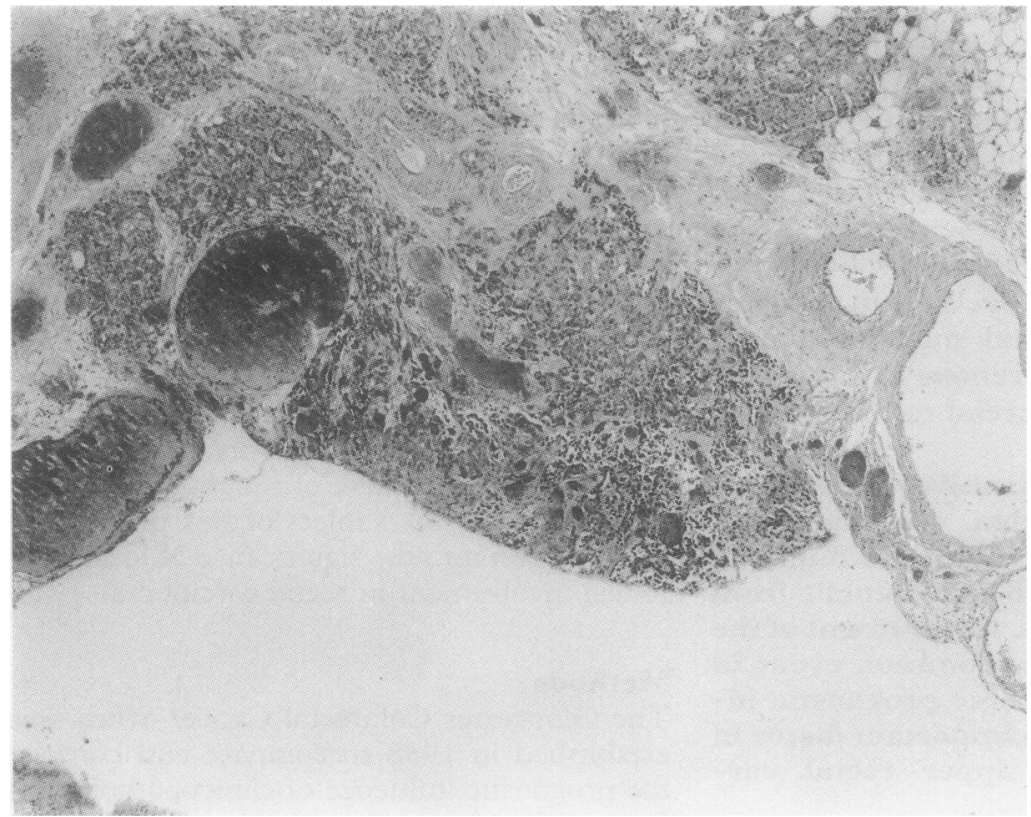

Figure 2 Local peritoneal involvement: group 3. A poorly differentiated carcinoma has involved the peritoneal surface of the upper rectum over a considerable distance. The vascular ectasia is a characteristic associated feature. (Haematoxylin and eosin; original magnification $\times 200$.) cision cases were excluded. Complete mesorectal excision ${ }^{910}$ was a favoured surgical technique, being documented in the operative records in $65 \%$ of cases.

In each patient analysis of endoscopic, surgical and pathological records confirmed the tumour to be a primary adenocarcinoma whose midpoint lay within the bounds of the anatomical rectum. Cases were deemed curative if the surgeon and/or the pathologist believed that all tumour had been removed by the end of the surgical procedure. Each patient was regularly followed up with surgical outpatient assessment and close cooperation of general practitioners. All clinical, pathological followup and survival data were stored on a computer database and regularly updated by one research officer (KJB). The median follow up was 30 months. Local recurrence in the pelvis was detected by clinical means and confirmed, where possible, by histological, cytological or radiological methods in accordance with previous studies. ${ }^{810}$ Intraperitoneal recurrence was recognised only at the time of laparotomy subsequent to the primary rectal resection and was confirmed by histological and/or cytological methods. Survival time was calculated from the date of surgery to the date of death or last follow up, with times censored for patients dying of causes unrelated to rectal cancer and those still alive. Cause of death was established by necropsy or, in the absence of a postmortem examination, the judgement was made upon careful assessment of the clinical course of the patient. If there was any doubt concerning the cause of death, the survival time was censored at the date of death. Pathological factors were tested for prognostic significance by means of the log rank test. ${ }^{14}$ Those factors found to have prognostic significance at a level of $p<0.1$ were entered into a stepwise Cox regression model ${ }^{15}$ to test for independent prognostic significance for survival.

\section{PATHOLOGICAI ASSESSMENT}

In each case pathological assessment of the resection specimen was undertaken in a standardised meticulous fashion by one pathologist (NAS). This involved the harvesting of all lymph nodes (mean lymph node harvest 21.4 ), comprehensive sampling of the primary tumour for histology (mean number of tumour blocks $6 \cdot 2$ ) and assessment of the relation of the tumour to the closest mesorectal resection margin according to the method of Quirke et al. ${ }^{8}$ The relation of the tumour to the peritoneal surface was initially assessed at the time of dissection and at least two blocks were taken from the area where the tumour was closest to the anterior peritoneal surface. Where tumour was demonstrated histologically to be close to the peritoneum, multiple levels were cut through the blocks to assess fully the proximity of the tumour to the peritoneal surface in histological terms. Local peritoneal involvement was assessed histologically in four groups: group 1, tumour well clear of closest peritoneal surface; group 2, mesothelial inflammatory/hyperplastic reaction with tumour close to but not actually 


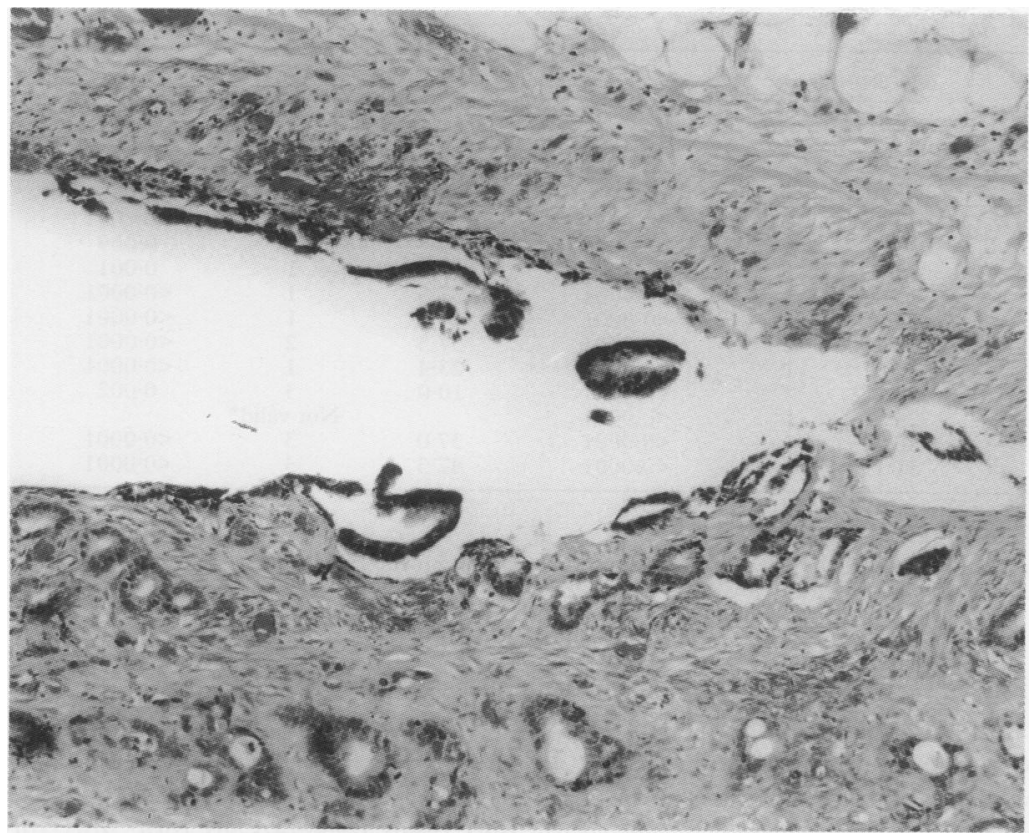

Figure 3 Local peritoneal involvement: group 4. This peritoneal infolding of the upper rectum is extensively infiltrated by a moderately differentiated adenocarcinoma. Three tumour cell groups are apparently lying free, effectively in the peritoneal cavity.

(Haematoxylin and eosin; original magnification $\times 200$.)

present at the peritoneal surface; group 3, tumour present at peritoneal surface with inflammatory reaction/mesothelial hyperplasia/ "ulceration" (fig 2); and group 4, tumour cells demonstrated free in peritoneum and evidence of adjacent "ulceration" (fig 3).

Histological assessment also involved analysis of all morphological parameters believed to be of prognostic significance in rectal carcinoma: tumour grade, ${ }^{16}$ tumour lymph node involvement, ${ }^{1718}$ number of involved lymph nodes, ${ }^{119}$ high tie lymph node involvement, ${ }^{5}$ extent of local spread, ${ }^{19}{ }^{20}$ lymphocytic infiltrate at advancing margin of tumour, ${ }^{21}$ quality of advancing margin, ${ }^{19}$ mesorectal margin involvement, ${ }^{8}$ fibrosis, ${ }^{22}$ associated adenomas, ${ }^{23}$ and extramural venous spread. $^{24}$ The association between local peritoneal involvement and each of these parameters was assessed using Fisher's exact test.

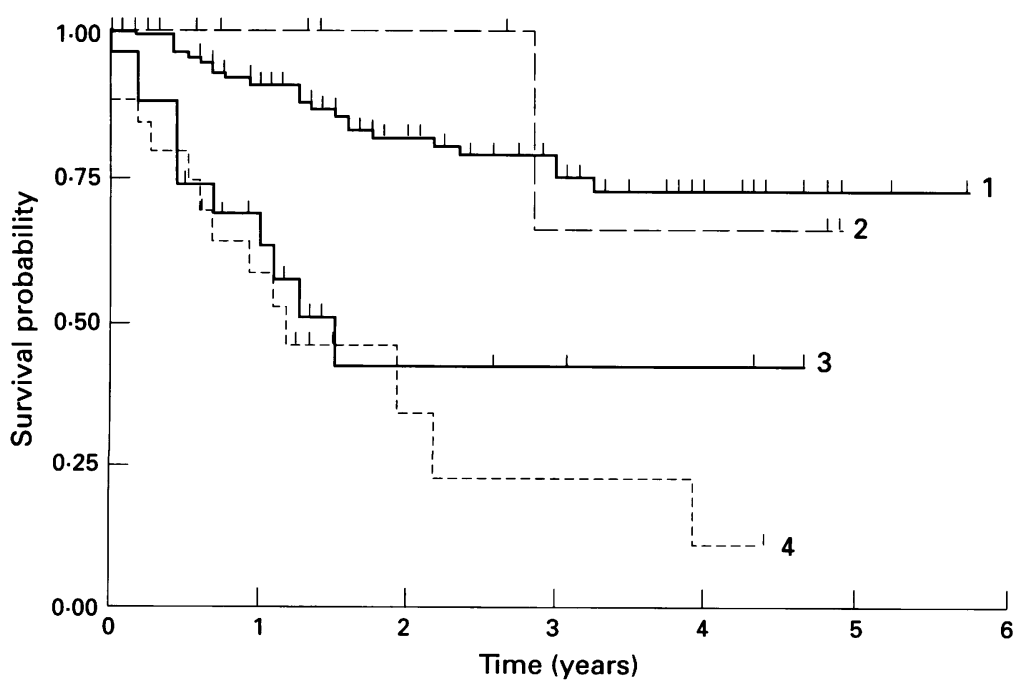

Figure 4 Kaplan-Meier cumulative survival curve for peritoneal involvement local peritoneal involvement groups 1 to 4) in all cases.
Table 1 Local peritoneal involvement in rectal carcinoma

\begin{tabular}{lc}
\hline Group 1 & $143(68 \cdot 4 \%)$ \\
Group 2 & $12(5 \cdot 7 \%)$ \\
Group 3 & $28(13 \cdot 4 \%)$ \\
Group 4 & $26(12 \cdot 4 \%)$ \\
\hline
\end{tabular}

\section{Results}

Local peritoneal involvement was demonstrated in $54(25.8 \%)$ of the 209 resected specimens. Of these, $26(12.4 \%)$ also showed tumour cells apparently free within the peritoneum on histological examination (fig 3) (table 1). Local peritoneal involvement was more common in women than in men. In men local peritoneal involvement was present in 27 $(21.7 \%)$ of 124 patients whilst in women 27 $(31.7 \%)$ of 85 showed local peritoneal involvement. Local peritoneal involvement also correlated with palliative surgery $(p<0.001)$, poor tumour differentiation $(p<0.001)$, increasing tumour size (as determined by surface area) $(p<0.001)$, the presence of lymph node involvement $(p<0.001)$, and tumour site (as determined by operation type, namely anterior resection versus abdomino-perineal excision) $(\mathrm{p}<0.001)$. On univariate analysis, local peritoneal involvement was significantly associated with an adverse prognosis in curative resections only (164 cases: $p=0.002$ ) and in curative and palliative cases combined (209 cases: $p<0 \cdot 0001)$. Figure 4 demonstrates the influence of local peritoneal involvement on survival for all patients. Table 2 shows univariate survival analysis for all clinicopathological factors analysed. The results of Cox regression analysis are shown in table 3. Parameters of independent prognostic influence were advancing margin, lymph node involvement and peritoneal involvement in all cases and extent of spread, lymph node involvement, highest node involvement, and extramural venous spread in curative cases.

With a median follow up of 30 months, local recurrence has been demonstrated in 25 $(12.0 \%)$ cases (table 4$)$. Thirteen $(52 \%)$ of these cases had been deemed palliative because pathological analysis of the resection specimen had demonstrated tumour at the deep (mesorectal) resection margin which can be considered the most likely cause of local recurrence (table 4: cases 1-13). Local peritoneal involvement was present in four of these cases and it is possible that this may have contributed to local recurrence. In six patients local peritoneal involvement, but not mesorectal resection involvement, was present in the original resection specimen of patients with upper rectal carcinoma, of which five showed tumour cells apparently free in the peritoneal space on histological section (local peritoneal involvement group 4) (table 4: cases 14-19).

Recurrence within the peritoneal cavity has been defined very strictly, with confirmation by histological and/or cytological methods to ensure that intraperitoneal disease is not related to the complications of surgery (especially adhesions). Three cases with pelvic recurrence have also shown intraperitoneal recurrence (table 4). One (case 15) showed local peritoneal 
Table 2 Univariate analysis for survival in rectal carcinoma

\begin{tabular}{|c|c|c|c|c|c|c|}
\hline \multirow[b]{2}{*}{ Variable } & \multicolumn{3}{|c|}{ All patients $(n=209)$} & \multicolumn{3}{|c|}{ Curative only $(n=164)$} \\
\hline & Logrank & $D F$ & $p$ & Logrank & $D F$ & $p$ \\
\hline $\begin{array}{l}\text { Differentiation } \\
\text { Tumour type } \\
\text { Extent of spread } \\
\text { Fibrosis } \\
\text { Lymphocytic infiltrate } \\
\text { Advancing margin } \\
\text { Extramural venous spread } \\
\text { Lymph node involvement } \\
\text { Highest node involvement } \\
\text { Peritoneal involvement } \\
\text { Deep margin involvement } \\
\text { Dukes' stage } \\
\text { Jass score }\end{array}$ & $\begin{array}{r}49 \cdot 7 \\
5 \cdot 6 \\
50 \cdot 5 \\
22 \cdot 6 \\
18 \cdot 9 \\
73 \cdot 0 \\
35 \cdot 8 \\
58 \cdot 7 \\
30 \cdot 0 \\
39 \cdot 2 \\
26 \cdot 5 \\
50 \cdot 14 \\
51 \cdot 14\end{array}$ & $\begin{array}{l}2 \\
1 \\
3 \\
2 \\
1 \\
1 \\
1 \\
2 \\
1 \\
3 \\
1 \\
3 \\
3\end{array}$ & $\begin{array}{l}<0.0001 \\
0.06 \\
<0.0001 \\
<0.0001 \\
<0.0001 \\
<0.0001 \\
<0.0001 \\
<0.0001 \\
<0.0001 \\
<0.0001 \\
<0.0001 \\
<0.0001 \\
<0.0001\end{array}$ & $\begin{aligned} 32 \cdot 8 \\
5 \cdot 1 \\
24 \cdot 3 \\
9 \cdot 5 \\
10 \cdot 8 \\
37 \cdot 5 \\
24 \cdot 4 \\
57 \cdot 3 \\
23 \cdot 4 \\
10 \cdot 0 \\
\\
37 \cdot 0 \\
47 \cdot 3\end{aligned}$ & $\begin{array}{l}2 \\
1 \\
3 \\
2 \\
1 \\
1 \\
1 \\
2 \\
1 \\
3 \\
\text { Not valid* } \\
3 \\
3\end{array}$ & $\begin{array}{c}<0.0001 \\
0.02 \\
<0.0001 \\
0.009 \\
0.001 \\
<0.0001 \\
<0.0001 \\
<0.0001 \\
<0.0001 \\
0.002 \\
\\
<0.0001 \\
<0.0001\end{array}$ \\
\hline
\end{tabular}

* All cases with deep margin involvement were considered palliative.

$\mathrm{DF}=$ degrees of freedom.

Patient age, sex, tumour size, and the presence of adenomas showed no significant prognostic influence.

involvement only at the time of primary surgery and intraperitoneal recurrence necessitated laparotomy. Two showed both mesorectal margin involvement and local peritoneal involvement (cases 4 and 11); both showed massive intraperitoneal disease at laparotomy. Either mesorectal margin involvement or local peritoneal involvement can be considered the cause of this transcoelomic spread although local peritoneal involvement would seem the more likely on anatomical grounds.

Three patients with low rectal cancer but without mesorectal resection margin or local peritoneal involvement subsequently re-presented with local pelvic recurrence. In one the distal margin of excision was involved by tumour at the time of primary surgery (table 4: case 22). In the second a Dukes' A carcinoma recurred also as an intramural tumour and, because of this, we consider intraluminal seeding of tumour cells at or before the original operation to be a likely cause of recurrence (table 4: case 20). Intramural seeding probably also accounts for a third lower rectal carcinoma recurrence as this patient had multiple intraanastamotic tumours at the time of recurrence (table 4: case 21). Two patients with middle rectal carcinomas (one Dukes' $B$ and one Dukes' C1) but with neither mesorectal margin involvement nor local peritoneal involvement developed pelvic recurrence. Both cases showed extensive extramural venous spread in the mesorectum which we consider the likely cause of local recurrence (table 4: cases 23 and 24). Finally, one patient with upper rectal carcinoma had shown spread in continuity with the bladder without pathological evidence of resection margin or local peritoneal involvement at the time of surgery (table 4: case 25). This had been resected en bloc and the operation considered curative. Subsequent local recurrence is almost certainly related to this tumour spread, either within the peritoneum and not demonstrable histologically or related to recurrence of tumour from within the bladder wall.

Of the 25 patients with local recurrence, 22 have died of carcinomatosis due to carcinoma of the rectum with a survival time from the original surgery varying from five to 51 months. Two remain in clinical remission at 39 and 54 months (cases 20 and 22, respectively); both had undergone further resections after pelvic recurrence. Case 17 with probable local peritoneal involvement induced local recurrence is alive but with recurrent disease at 53 months. All of the 13 patients with local recurrence due to mesorectal margin involvement have died of carcinomatosis, five within eight months of initial rectal surgery.

Fifty four $(26 \%)$ patients demonstrated local peritoneal involvement at the time of rectal resection. If local peritoneal involvement is considered a factor in pelvic recurrence, it is pertinent to examine the history of those patients in whom local peritoneal involvement was shown but in whom unequivocal pelvic/ intraperitoneal recurrence has not been demonstrated subsequently. Of the 40 patients in this category, 15 have died of carcinomatosis,

Table 3 Cox regression analysis for all patients and for curative surgery

\begin{tabular}{|c|c|c|c|c|}
\hline Variable & Classification & Hazard ratio & $95 \% C I$ & $p$ \\
\hline $\begin{array}{l}\text { Curative surgery only (164 patients) } \\
\text { Local spread }\end{array}$ & $\begin{array}{l}\text { none/mild } v \text { ext } \\
\text { moderate } v \text { ext }\end{array}$ & $\begin{array}{l}0 \cdot 18 \\
0.64\end{array}$ & $\begin{array}{l}(0 \cdot 04,0 \cdot 73) \\
(0 \cdot 26,1 \cdot 56)\end{array}$ & $0.006^{*}$ \\
\hline $\begin{array}{l}\text { Extramural venous spread } \\
\text { Lymph node involvement }\end{array}$ & $\begin{array}{l}\text { present } v \text { absent } \\
0 v>4 \\
1-4 v>4\end{array}$ & $\begin{array}{l}3 \cdot 11 \\
0 \cdot 07 \\
0 \cdot 28\end{array}$ & $\begin{array}{l}(1.03,9.34) \\
(0.01,0.57) \\
(0.11,0.71)\end{array}$ & $\begin{array}{c}0.04 \\
<0.001 *\end{array}$ \\
\hline Highest lymph node involved & yes $v$ no & $9 \cdot 71$ & $(3 \cdot 21,29 \cdot 4)$ & $<0.001$ \\
\hline $\begin{array}{l}\text { All patients }(n=209) \\
\text { Advancing margin } \\
\text { Lymph node involvement }\end{array}$ & $\begin{array}{l}\text { diffuse } v \text { circ } \\
0 v>4 \\
1-4 v>4\end{array}$ & $\begin{array}{l}7 \cdot 2 \\
0 \cdot 25 \\
0 \cdot 50\end{array}$ & $\begin{array}{l}(2 \cdot 9,17 \cdot 7) \\
(0 \cdot 08,0 \cdot 8) \\
(0 \cdot 26,0.94)\end{array}$ & $\begin{array}{r}<0.001 \\
0.006^{*}\end{array}$ \\
\hline $\begin{array}{l}\text { Highest lymph node involved } \\
\text { Peritoneal involvement }\end{array}$ & $\begin{array}{l}\text { yes } v \text { no } \\
3 v 1 \text { and } 2 \\
4 v 1 \text { and } 2\end{array}$ & $\begin{array}{l}2 \cdot 8 \\
1 \cdot 4 \\
2 \cdot 1\end{array}$ & $\begin{array}{l}(1 \cdot 3,6 \cdot 1) \\
(0 \cdot 6,2 \cdot 9) \\
(1 \cdot 0,4 \cdot 2)\end{array}$ & $\begin{array}{l}0.008 \\
0.04^{*}\end{array}$ \\
\hline
\end{tabular}

$\mathrm{CI}=$ confidence interval; circ $=$ circumscribed; ext $=$ extensive; ${ }^{*} \mathrm{p}$ value for trend. 
Table 4 Pelvic recurrence of rectal carcinoma

\begin{tabular}{|c|c|c|c|c|c|c|c|c|}
\hline $\begin{array}{l}\text { Case } \\
\text { No. }\end{array}$ & $\begin{array}{l}\text { Age } \\
\text { (Years) }\end{array}$ & Sex & Site & $\begin{array}{l}\text { Dukes' } \\
\text { stage }\end{array}$ & $M R M I$ & $\begin{array}{l}\text { LPI } \\
\text { group }\end{array}$ & $\begin{array}{l}\text { Suggested cause } \\
\text { of recurrence }\end{array}$ & Comments \\
\hline 1 & 51 & $\mathbf{F}$ & Upper & $\mathrm{Cl}$ & yes & 4 & MRMI/LPI & DRC $8 \mathrm{~m}$ \\
\hline 2 & 60 & $\mathrm{~F}$ & Lower & $\mathrm{C} 2$ & yes & 1 & MRMI & DRC $5 \mathrm{~m}$ \\
\hline 3 & 62 & $\mathbf{M}$ & Lower & C2 & yes & 1 & MRMI & DRC $7 \mathrm{~m}$ \\
\hline $4^{*}$ & 68 & $\mathbf{F}$ & Upper & C1 & yes & 4 & MRMI/LPI & DRC $23 \mathrm{~m}$ \\
\hline 5 & 69 & F & Lower & C1 & yes & 1 & MRMI & DRC $11 \mathrm{~m}$ \\
\hline 6 & 71 & $\mathbf{M}$ & Lower & B & yes & 1 & MRMI & DRC $51 \mathrm{~m}$ \\
\hline 7 & 72 & $\mathbf{F}$ & Middle & $\mathbf{B}$ & yes & 4 & MRMI/LPI & DRC $14 \mathrm{~m}$ \\
\hline 8 & 74 & $\mathbf{M}$ & Lower & $\mathbf{B}$ & yes & 1 & MRMI & DRC $5 \mathrm{~m}$ \\
\hline 9 & 75 & M & Lower & $\mathrm{C} 2$ & yes & i & MRMI & DRC $19 \mathrm{~m}$ \\
\hline 10 & 75 & $\mathbf{F}$ & Middle & $\mathrm{C} 1$ & yes & 1 & MRMI & DRC $15 \mathrm{~m}$ \\
\hline $11^{*}$ & 79 & F & Middle & B & yes & 3 & MRMI/LPI & DRC $13 \mathrm{~m}$ \\
\hline 12 & 84 & $\mathrm{~F}$ & Middle & C1 & yes & 4 & MRMI/LPI & DRC $13 \mathrm{~m}$ \\
\hline 13 & 89 & $\mathbf{M}$ & Middle & B & yes & 1 & MRMI & DRC $5 \mathrm{~m}$ \\
\hline 14 & 54 & $\mathbf{M}$ & Upper & C2 & no & 3 & LPI & DRC $5 \mathrm{~m}$ \\
\hline $15^{*}$ & 67 & $\mathbf{F}$ & Upper & $\mathrm{C} 1$ & no & 4 & LPI & DRC $26 \mathrm{~m}$ \\
\hline 16 & 68 & $\mathbf{M}$ & Middle & $\mathrm{Cl}$ & no & 4 & LPI & DRC $6 \mathrm{~m}$ \\
\hline 17 & 68 & $\mathrm{~F}$ & Middle & $\mathrm{C} 1$ & no & 4 & LPI & $\mathrm{AMD} 53 \mathrm{~m}$ \\
\hline 18 & 69 & F & Upper & $\mathrm{Cl}$ & no & 4 & LPI & DRC $47 \mathrm{~m}$ \\
\hline 19 & 77 & $\mathbf{F}$ & Upper & $\mathrm{C} 1$ & no & 4 & LPI & DRC $11 \mathrm{~m}$ \\
\hline 20 & 66 & $\mathbf{M}$ & Lower & A & no & 1 & ILS & $A \& W \quad 39 \mathrm{~m}$ \\
\hline 21 & 68 & $\mathbf{F}$ & Lower & $\mathrm{Cl}$ & no & 1 & ILS & DRC $19 \mathrm{~m}$ \\
\hline 22 & 54 & $\mathbf{M}$ & Lower & B & no & 1 & Tumour at distal margin & $A \& W 54 \mathrm{~m}$ \\
\hline 23 & 41 & $\mathbf{M}$ & Middle & B & no & 1 & Extramural venous spread & DRC $17 \mathrm{~m}$ \\
\hline 24 & 75 & $\mathbf{M}$ & Middle & $\mathrm{C} 1$ & no & 1 & Extramural venous spread & DRC $40 \mathrm{~m}$ \\
\hline 25 & 77 & $\mathbf{M}$ & Middle & $\mathrm{C} 1$ & no & 2 & Spread to bladder & DRC $26 \mathrm{~m}$ \\
\hline
\end{tabular}

MRMI = mesorectal resection margin involvement; $L P I=$ local peritoneal involvement; ILS = intraluminal seeding; DRC $=$ died of carcinomatosis due to carcinoma of rectum; $A M D=$ alive with metastatic disease; $A \& W=$ alive and in clinical remission; $m=$ months.

* Three patients also showed intraperitoneal recurrence as well as pelvic recurrence.

five have died of unrelated causes and 20 are still alive.

There were also 17 patients with histological evidence of mesorectal resection margin involvement in whom local recurrence has not been confirmed. Of these 17 patients, six have died of carcinomatosis and three of unrelated disease; eight are still alive.

\section{Discussion}

The prognostic significance of peritoneal involvement is well known in gastric cancer ${ }^{25}$ and ovarian cancer. ${ }^{26}$ However, little attention has been paid to this phenomenon in colorectal cancer, despite the fact that peritoneal spread is said to be an important mode of death in colonic cancer. ${ }^{27} 28$ Of the major staging classification systems, only the ACPS system ${ }^{6}$ and the TNM classification ${ }^{29}$ include a histological assessment of serosal involvement. In the ACPS system relatively few cases fall into the serosal involvement category (B2: 5\%) largely because of the sequential nature of the system whilst, in the TNM system, T4 stage indicates involvement of other organs/structures as well as invasion of the visceral peritoneum. ${ }^{29}$ Therefore, the full prognostic importance of peritoneal involvement is obscured in both classifications. In a parallel study to the one reported here, local peritoneal involvement was demonstrated in $58 \%$ of an unselected series of 287 colonic carcinoma cases and was a consistent predictor of future intraperitoneal recurrence ${ }^{30}$ Furthermore, cytological analyses of peritoneal aspirates at the time of surgery have demonstrated intraperitoneal carcinoma cells in $35 \%$ of colorectal carcinoma cases by cytological and immunohistochemical methods. ${ }^{31}$ These studies demonstrate the potential importance of this feature as a predictor of intraperitoneal and pelvic recurrence.
In this study local peritoneal involvement was seen in $54(25.8 \%)$ cases of rectal cancer, particularly in women, in whom more of the surface area of the upper rectum is invested by peritoneum. The serosa on the anterior surface of the upper rectum is closely applied to the outer longitudinal muscularis propria with little intervening fibro-fatty connective tissue. Therefore, the relative frequency of peritoneal involvement in upper rectal cancer is not unexpected as the great majority of rectal tumours are at least Dukes' B stage with spread beyond the muscularis propria. The prognostic significance of peritoneal involvement in this study is noteworthy, particularly as it is a relatively unusual feature and yet it does seem to confer a small independent prognostic disadvantage. It should be stressed that this study is purely a histological one and that local peritoneal involvement may not be definitive evidence that viable tumour cells are present in the peritoneal cavity. Local peritoneal involvement should be regarded as a useful marker of potential spread across the peritoneum or in the pelvis. Superficially, the division of peritoneal involvement into four groups would not appear to provide much additional data. However, in our study of colonic cancer, the division into the four groups is of strong independent prognostic significance in patients undergoing curative surgery, there being significant differences in survival between groups 1 and 2 and groups 3 and $4 .^{30}$ Furthermore, group 4 local peritoneal involvement is more likely to predict both intraperitoneal recurrence in colonic cancer and pelvic recurrence in rectal cancer than group 3 .

Local recurrence rates in this series were $6 \cdot 2 \%$ (curative cases only) and $12.4 \%$ (all cases), figures comparable with other series in which complete mesorectal excision was practised. ${ }^{103233}$ Our data have also confirmed that locoregional recurrence is an almost uniformly lethal event in rectal carcinoma. Median 
follow up time is currently only 30 months and therefore survival data has to be considered provisional. Nevertheless, the data on local recurrence would seem more conclusive as previous work has shown that most local recurrences will have presented within this time. ${ }^{811}$ The cause of local recurrence in rectal cancer has been an enigmatic and controversial subject for many years. Theories abound as to its cause. The compelling data of Heald et $a l^{91032}$ argue that mesorectal tumour extension is the most important factor in local recurrence and that complete mesorectal excision will substantially reduce local recurrence rates. Our data show that mesorectal tumour extension is the likely cause of local recurrence in at least half of all cases, confirming its role as the most important factor in local recurrence. Complete mesorectal clearance was achieved in most cases in this series, thus other factors predisposing to local recurrence have become more influential. Local peritoneal involvement, without any other major predictor of recurrence, was present in six of 25 cases and was also present along with mesorectal margin involvement in an additional five cases. Intraluminal seeding is likely to be the determinant of local recurrence in a small proportion of cases. Intraluminal washouts were performed in the majority of cases and it is likely that this practice has substantially reduced the incidence of intraluminal seeding.

This series has emphasised the importance of the pathological assessment of circumferential (deep, mesorectal) spread of rectal carcinoma, particularly with respect to the mesorectal resection margin and the peritoneal surface, especially for the assessment of potential local recurrence. Traditional prognostic parameters such as grade, tumour type, Dukes' stage, and Jass grade are certainly less important in this regard. The analysis of mesorectal resection margin involvement and peritoneal spread is not merely of prognostic importance: the identification, at the time of primary surgery, of cases with significant local recurrence potential could permit the early institution of adjuvant therapy. Early radiotherapy to the pelvic bed may enable control of local disease; the potential of intraperitoneal chemotherapy has not been rigorously pursued in colorectal cancer. The relatively common finding of peritoneal involvement in rectal cancer, and in colonic cancer, ${ }^{30}$ emphasises the importance of the practice of peritoneal washout at primary surgery.

There are a significant number of patients with both local peritoneal involvement and mesorectal margin involvement who have not exhibited subsequent local recurrence. About half the patients in these categories have died and it is likely that metastatic disease was particularly aggressive in these cases, not permitting presentation with local disease. Nevertheless, in both groups there are patients who are alive without demonstrable local recurrence and it is conceded that the presence of mesorectal margin and local peritoneal involvement may not necessarily be entirely predictive for local recurrence. In other series in which mesorectal margin involvement has been shown to be strongly associated with local recurrence, not all cases have subsequently demonstrated local recurrence. ${ }^{834}$ Our findings show that both are good markers for such recurrence and may alone be sufficient evidence upon which to instigate early adjuvant therapy. In support of the role of local peritoneal involvement in promoting and predicting pelvic recurrence, all three cases with documented intraperitoneal recurrence had displayed group 4 local peritoneal involvement.

Pathological stage remains the most powerful predictor of overall prognosis after surgery for rectal cancer. ${ }^{35}$ Other factors are of important prognostic significance, however, and of these mesorectal margin involvement and local peritoneal involvement appear to be of increasing importance particularly for assessing the potential for local recurrence, an event which itself has a major influence on prognosis, and may guide oncologists to select patients most likely to benefit from adjuvant therapies.

We are very grateful to $\mathrm{Mr}$ W H F Thomson and $\mathrm{Mr} \mathrm{M} \mathrm{W} \mathrm{L}$ Gear for their help and constructive advice during this and other studies of colorectal cancer. We would also acknowledge the cooperation and diligence of all other Gloucester surgeons: Mr B P Heather, Mr J J Earnshaw, Mr J O Kilby, Mr H Barr, Mr D J Jones, and Mr D G Calvert, and the general practitioners of West Gloucestershire, who have ensured comprehensive surof veillance of all patients in the Gloucester colorectal cancer studies. We would also like to thank the Histopathology MLSO staff, Gloucestershire Royal Hospital, for their cooperation. The support of the Imperial Cancer Research Fund, and in particular Professor Nicholas A Wright, is gratefully acknowledged. Mr
Steve Cashmore provided illustrative support to his usual high Steve Cashr
standard

1 Dukes CE. The classification of cancer of the rectum. $f$ Pathol Bacteriol 1932;35:323-32.

2 Fenoglio-Preiser CM, Pascal RR. Other tumours of the large intestine. In: Whitehead $R$, ed. Gastrointestinal and oesophageal pathology. Edinburgh: Churchill Livingstone, 1989:747-68.

3 Astler VB, Coller FA. The prognostic significance of direct extension of carcinoma of the colon and rectum. Ann Surg 1954;139:846-51.

4 Kirklin MD, Dockerty MB, Waugh JM. The role of the peritoneal reflection in the prognosis of carcinoma of the rectum and sigmoid colon. Surg Gynecol Obstet 1949;88: 326-31.

5 Dukes CE, Bussey HJR. The spread of rectal cancer and its effect on prognosis. Br $\mathcal{F}$ Cancer 1958;12:1016-23.

6 Davis NC, Newland RC. Terminology and classification of colorectal adenocarcinoma; the Australian clinico-pathocolorectal adenocarcinoma; the Australian clinico-patho-

logical staging system. Aust NZ $\mathcal{F}$ Surg 1983;53:211-21.
7 Shepherd NA. Pathological prognostic factors in colorectal cancer. In Kirkham N, Lemoine NR, eds. Progress in cancer. In Kirkham N, Lemoine NR, eds. Progress in
pathology. 2nd edn. Edinburgh: Churchill Livingstone (in press)

8 Quirke P, Dixon MF, Durdey P, Williams NS. Local recurrence of rectal adenocarcinoma due to inadequate surgical resection. Histopathological study of lateral tumour spread and surgical excision. Lancet 1986;ii:9969.

9 Heald RJ, Ryall RDH. Recurrence and survival after total mesorectal excision for rectal cancer. Lancet 1986;i:147982.

10 Macfarlane JK, Ryall RDH, Heald RJ. Mesorectal excision for rectal cancer. Lancet 1993;341:457-60.

11 Morson BC, Vaughan EG, Bussey HJR. Pelvic recurrence after excision of rectum for carcinoma. BMF 1963;ii: after excis 18 .

12 Umpleby HC, Williamson RCN. Viability of exfoliated colorectal carcinoma cells. Br f Surg 1984;71:659-63.

13 Williams PL, Warwick R, Dyson M, Bannister LH (eds) Gray's Anatomy. Edinburgh: Churchill Livingstone, 1989: Gray's
1369.

14 Peto $R$, Pike MC, Armitage P, Breslow NF, Cox DR Howard SV, et al. Design and analysis of randomised clinical trials requiring prolonged observation of each patient. II Analysis and examples. Br $\mathcal{F}$ Cancer 1977;35: 1-39.

15 Cox DR. Regression models and life tables (with discussion). $\mathcal{F} R$ Statist Soc $B$ 1972;34:187-220.

16 Jass JR, Atkin WS, Cuzick J, Bussey HJR, Motson BC 
Northover JMA, et al. The grading of rectal cancer: historical perspectives and a multivariate analysis of 447 cases. Histopathology 1986;10:437-59.

17 Sasaki O, Atkin WS, Jass JR. Mucinous carcinoma of the rectum. Histopathology 1987;11:259-72.

18 Shepherd NA, Saraga EP, Love SB, Jass JR. Prognostic factors in colonic cancer. Histopathology 1989;14:613-20

19 Jass JR, Love SB, Northover JMA. A new prognostic classification of rectal cancer. Lancet 1987;i:1303-6.

20 Cawthorn SJ, Parurns DV, Gibbs NM, A'Hern RP, Caffarey Broughton CIM, Marks CG. Extent of mesorectal spread Broughton CIM, Marks CG. Extent of mesorectal spread factors after surgery for rectal cancer. Lancet 1991;335: factors afte

21 Jass JR. Lymphocytic infiltration and survival in rectal cancer. $f$ Clin Pathol 1986;39:585-9.

22 Halvorsen TB, Seim E. Association between invasiveness, inflammatory reaction, desmoplasia and survival in colorectal cancer. $\mathcal{f}$ Clin Pathol 1989;42:162-6.

23 Kronborg O, Hage E, Fenger C, Deichgraeber E. Do synchronous adenomas influence prognosis after radical surgery for colorectal cancer? A prospective study. Int $\mathcal{f}$ Colorectal Dis 1986;1:99-103.

24 Talbot IC, Ritchie S, Leighton MH, Hughes AO, Bussey HJR, Motson BC. The clinical significance of invasion of HJR, Motson BC. The clinical significance of invasio
veins by rectal cancer. Br $₹$ Surg 1980;67:439-42.

25 Boku T, Nakane Y, Minoura T, Takada H, Yamamura M Hioki $\mathrm{K}$, et al. Prognostic significance of serosal invasion and free intraperitoneal cancer cells in gastric cancer. $\mathrm{Br}$ f Surg 1990;77:436-39.

26 Shepherd JH. Surgical management of ovarian cancer. In
Shepherd JH, Monaghan JM, eds. Clinical gynaecological oncology. Oxford: Blackwell Scientific Publications, 1985: 187-207.

27 Willett CG, Tepper JE, Cohen AM, Orlow E, Welch CE. Failure patterns following curative resection for colonic carcinoma. Ann Surg 1984;200:685-90.

28 Alley PG, McNee RK. Age and sex differences in right colon cancer. Dis Colon Rectum 1986;29:227-9.

29 UICC In: Hermanek P, Sobin LH, eds. TNM classification of malignant tumours. 4th edn, 2nd revision. Berlin: SpringerVerlag, 1992 .

30 Shepherd NA, Baxter KJ, Love SB. Local peritoneal involvement in colonic cancer: a neglected prognostic parameter [aboric cancer: a neglected progr

31 Leather AJM, Kocjan G, Savage F, Hu W, Yiu C-Y, Boulos $\mathrm{PB}$, et al. Detection of free malignant cells in the peritoneal cavity before and after resection of colorectal cancer. $D i s$ Colon Rectum 1994;38:814-19.

32 Heald RJ, Husband EM, Ryall RDH. The mesorectum in rectal cancer surgery-the clue to pelvic recurrence. $\mathrm{Br} \mathcal{f}$ Surg 1982;69:613-16.

33 Dixon AR, Maxwell WA, Thornton Holmes J. Carcinoma of the rectum: a ten year experience. $B r \mathcal{F}$ Surg 1991;78: 308-11.

34 Adam IJ, Mohamdee MO, Martin IG, Scott N, Finan $\mathrm{PJ}$, Johnston $\mathrm{D}$, et al. Role of circumferential margin
involvement in the local recurrence of rectal cancer. Lancet involvement in the

35 Harrison JC, Dean PJ, El-Zeky F, van der Zwaag R. From Dukes through Jass: pathological prognostic indicators in rectal cancer. Hum Pathol 1994;25:498-505. 